\title{
Hispanoamericanos en Londres a comienzos del siglo XIX
}

\author{
manuel Ortuño Martínez *
}

\begin{abstract}
RESUMEN ABSTRACT
Durante las primeras décadas en del siglo xix en Londres coincidieron los exiliados liberales procedentes de España y los patriotas insurgentes de las provincias de América. Desde Miranda a Rocafuerte, pasando por Bello, Alvear, Moreno, Sarratea, Teresa de Mier, Palacio Fajardo, Irisarri, Belgrano, los Fagoaga y Alamán, buscaban el apoyo de la Gran

Bretaña y el reconocimiento de la independencia, que se retrasó hasta 1824. Con ellos convivió en Londres Xavier Mina el joven liberal radical español que luchó) en México contra el absolutismo de Fernando VII.ad.

\author{
PALABRAS CLAVE \\ Insurgencia, Hispanoamérica, \\ liberales en Londres, \\ exilio liberal en Londres.
}

During the three first decade of the $X I X$ Century in London the Spanish Liberal exiles were living among the insurgents patriots coming from Spanish America, From Miranda to Rocafuerte through Bello, Alvear, Moreno, Sarratea, Teresa de Mier, Palacio Fajardo, Irisarri, Belgrano, the Fagoaga's and Alamán, all of them were seeking for the United Kingdom support and recognition to their Independence, finally arrived at 1824. the jound radical liberak Xavier Mina was there before he goes to Mexico to fight against the Ferdinand VII absolutism.

\section{KEY WORDS}

Insurgency, Spainish America, liberals in London, American Liberal Exiles in London.
\end{abstract}

* Doctor en Historia de América. 
Parece una constante histórica. En las fracturas político-ideológicas que enfrentaron a las naciones europeas, pero también en los conflictos de carácter interno, Inglaterra y Londres se han solido constituir en lugar de asilo, centro de acogida, refugio de perseguidos, casa común abierta a los que sufren o se esfuerzan por reconstruir identidades o personalidades en proceso de destrucción.

Un antecedente próximo y muy cercano a la historia española, tuvo como escenario la ciudad de Londres en los primeros años del siglo xIX, coincidiendo con un momento de exaltación identitaria en las provincias de América, en cierta medida simultáneo a la invasión de la península Ibérica y la guerra de Independencia.

Londres, que habia sido desde algunas décadas anteriores lugar de visita o estancia de personajes eminentes, por riqueza o alcurnia, de científicos y hombres de pensamiento, se convirtió además en centro de atracción para los exiliados y perseguidos, tanto por los regímenes absolutistas como por las revoluciones continentales. En la capital británica coincidieron los radicales de ambos signos y en ella convivieron y proyectaron sus sueños de liberación o de reconquista.

Constituyen una curiosa galería de personajes polifacéticos, la mayoría de los cuales con el paso de los años llegó a ocupar posiciones de responsabilidad y liderazgo en sus países respectivos.

En abril de 1815 llegaba a Bristol y Londres Xavier Mina rodeado de un clima de interés como resonancia de los años de guerra contra Napoleón en España, su actuación inicial al fundar las guerrillas y el Corso Terrestre de Navarra en 1809, sus brillantes acciones paramilitares y sus iniciativas estratégicas de los primeros meses de 1810 relacionadas con Inglaterra y la apertura de un puerto en el Cantábrico, asi como cierta confusión nominal, consecuencia de la adopción de su apellido Mina por parte de su tío Francisco Espoz cuando Xavier cayó en poder de los franceses en la primavera de 1810.

Xavier Mina había estado encerrado en el castillo de Vincennes cerca de París, como prisionero de Estado de Napoleón durante 4 años, se había convertido al liberalismo radical bajo la influencia de ciertos ideólogos franceses enemigos del bonapartismo, regresó a España en mayo de 1814 como acérrimo constitucionalista opuesto al "golpe de estado" de Fernando VII y había protagonizado junto con su tío el primer intento insurreccional frente al "rey felón", golpe que terminó en fracaso y que le obligó a exiliarse en Francia y posteriormente trasladarse a Inglaterra.

En aquellos momentos su mayor interés residia en participar, tal y como se había comprometido en las prisiones de Burdeos y el "depósito de españoles" 
de Bayona, en las nuevas acciones antifernandinas programadas en julio de 1814 en Madrid y que consistían en apoyar el plan insurreccional de Porlier recluido en la Coruña. Su entrada en Inglaterra se produjo en medio del mayor sigilio y ningún medio de prensa se hizo eco de su llegada hasta varios meses después. Enseguida tomó contacto con los emigrados españoles, a través de Blanco White llegó al círculo de la Holland House y Lord Holland y se comunicó por carta con el Secretario de Estado británico Lord Castlereagh 1.

Pero al llegar a Londres se encontró ademas con otro grupo humano del que seguramente tenía algunas referencias y que llegó a influir notablemente en su conducta inmediata, obligándole a cambiar sus planes y a corregir su estrategia de político incipiente y de militar cada día mejor formado y preparado para la acción. Me refiero a los «patriotas» hispanoamericanos que se habían ido congregando en Londres y se movían por la capital del imperio británico en busca de ayudas y apoyos, morales y materiales, en favor de su lucha por la emancipación de las provincias o "colonias» de la América española.

Pretendo recoger, resumir y comentar en estas notas algunas de las investigaciones y estudios más recientes sobre la situación y las actuaciones de estos "patriotas de la emancipación" y el ambiente, propicio a una intervención exterior en Hispanoamérica, que tan decisivamente influyó en la actuación posterior del propio Xavier Mina? .

La primera década del siglo XIX en Londres, en lo que concierne a las relaciones entre Gran Bretaña y la América española, está dominada por la poderosa personalidad de Francisco Miranda el "Precursor», que permaneció en Europa de 1783 a 1810, participó en las luchas revolucionarias al lado de los franceses y convivió en París con otros criollos americanos con quienes concertó una serie de acciones en favor de la independencia. En 1797 en París firmó un acuerdo en el que se dice que también participó Pablo de Olavide y poco después se trasladó a Londres con la idea de comprometer al gobierno británico en sus planes. Ese mismo año, en Caracas tenía lugar el levantamiento de Gual y España.

Le siguieron muy pronto a Londres Antonio Nariño, neogranadino, que decepcionado por la frialdad británica regresó a Santa Fe y Pedro Jose Caro, entusiasmado por la labor que Miranda estaba desarrollando. Pedro Fermín

\footnotetext{
Ver mi tesis doctoral "Xavier Mina, un liberal español y su intervención en la Independencia de México", Universidad Complutense. Facultad de Geografía e Historia. Madrid, 1998. Incluye una amplia reproducción de la correspondencia diplomática de la época y los contactos de Xavier Mina con Lord Castlereagh y otros políticos británicos.

2 Ver la tesis doctoral a que me refiero en la nota anterior.
} 
de Vargas, también neogranadino, abandonó su tierra en 1791 y viajó de forma clandestina por Venezuela, Antillas y Filadelfia. Según Berruezo ${ }^{3}$, se trasladó a Europa y visitó España, Francia e Inglaterra, “inicando una relación con Caro y Miranda, que le admirará sinceramente». Consiguió ser recibido por Pitt en 1799 y en ese acto le entregó memoriales sobre América y el papel que Inglaterra debería tener en el proceso de su independencia.

Ese mismo año (1799) Miranda imprimió la Carta a los Españoles Americanos del jesuita peruano Juan Pablo Vizcardo y Guzmán ${ }^{4}$. Berruezo se refiere por extenso al papel de los jesuitas en el proceso de cambio de mentalidad que se estaba operando por aquellos años y la influencia que ejercieron en Europa y América. Vizcardo (a veces Viscardo) había viajado de Italia a Londres en 1782 y tuvo relaciones con Pitt, que recibió sus proyectos sobre la emancipación americana. Regresó a Italia dos años después pero entre 1792 y 1795 residió nuevamente en Londres donde recibia una pensión del gobierno inglés. Al parecer, escribió la carta entre 1790 y 1792 y cuando se produjo su muerte en 1798, dejó todos sus papeles al ministro de Estados Unidos en Londres, quien a su vez los legó a Miranda. "Miranda, dice Berruezo, despues de leerla, observó que incluía todas las quejas y demandas de los americanos y que por lo tanto sería un instrumento vital en su propaganda independentista» 5 .

García Gallo ${ }^{6}$ ha resumido los argumentos de la "Carta» en tres puntos: Un argumento geográfico, ya que América era la patria de los americanos, lejos de España, considerándose aquel continente como algo propio y diferente de la metrópoli. Un argumento de mayoría de edad a la que habrían accedido los americanos, con lo que tenían derecho a la emancipación y por último, que la tiranía, la falta de libertad, el despojo de riquezas, la desigualdad y el mal gobierno, estaban en contraposición a la libertad e igualdad consagradas en la antigua constitución española. Apoyándose en la corriente de pensamiento escolástico español, Vizcardo subrayaba que la tiranía anulaba la autoridad del príncipe.

En 1798 había Ilegado a Londres el joven Bernardo O'Higgins, por quien Miranda tuvo especial predilección, inspirando en él aquel fuerte deseo de libertad que tan decisivo seria en la vida del futuro presidente de

\footnotetext{
3 María Teresa BerRuezo LEON, La lucha de Hispanoamérica por su Independencia en Inglaterra. Ediciones de Cultura Hispánica. Madrid, 1989, pp. 27 y ss.

María Teresa BERRUEzo LEón, op. cit., pp. 55 y ss.

La primera edición de la "Carta" se imprimió en el original francés, con falso pie de im. prenta en Filadelfia. La edición española traducida por Miranda vio la luz en Londres en 1802.

"Alfonso Garcia Gallo, "El derecho indiano y la independencia de América». Revista de Estudios Políticos. Madrid, n. ${ }^{\circ} 60,1951$.
} 
Chile. Se hizo famoso el "Decálogo" que con el título de "Consejos de un viejo sur-americano a un joven patriota", escribió Miranda, dedicado a su discípulo. O'Higgins describió a Miranda como «inteligente e infatigable apóstol de la causa de Sudamérica" ${ }^{7}$.

Hacia 1803, Miranda y Vargas habían preparado un plan de acción por el que pretendian llegar a Trinidad y organizar desde alli una expedición libertadora destinada a México, pero este plan no salió adelante, en gran parte debido a la falta de interés de Vargas, que prefirió dedicarse a su afición por la botánica. Enfadado Miranda con Vargas, inclinado a empezar la liberación de América por México pero enfadado también con los ingleses, pasó un breve periodo de tiempo en Estados Unidos, que aprovechó para proyectar una expedición libertadora a Coro, que fracasó ante el desinterés general de sus habitantes. A su regreso a Inglaterra, en 1807, Miranda inició una frenética actividad propagandística, en la cresta de la ola de una coyuntura muy favorable, que parecía propiciar la puesta en marcha de un nuevo plan revolucionario. A pesar de todos los contratiempos y dificultades los tres años que permaneció en Londres estuvieron llenos de actividad creadora.

Uno de sus mejores amigos británicos, William Burke, se mostró dispuesto a recoger sus planteamientos y propuestas y fruto de la intensa colaboración entre ambos publicó en 1807 South American Independence or the emancipation of South America, the Glory and Interest of England y a principios de 1808 Additional Reasons for our inmediately emancipating Spanish America... A través de estos escritos de Burke, Miranda se empeñó en disipar cualquier interrogante sobre el justo derecho de los americanos a luchar por su independencia, exponiendo las razones prácticas que aconsejaban llevar a cabo ese proyecto, e insistiendo en las ventajas que tal resolución aportaría a la Gran Bretaña.

Miranda trató insistentemente de conseguir que avanzaran los preparativos ingleses para enviar una flota de guerra a los dominios americanos, especialmente a México. Se dice que Additional Reasons..., publicada en el año crucial de 1808 , tenía como finalidad propinar un impulso final a la todavía vacilante posición inglesa. Pero en 1808 el cambio de estrategia británica al aceptar el ofrecimiento de las recién formadas Juntas españolas, y la firma de una alianza frente a Napoleón, trajo como consecuencia la cancelación de los proyectos de ayuda a los patriotas americanos lo que no impidió la labor periodística de Miranda, sirvéndole incluso de acicate y estímulo.

Entre 1808 y 1810 Miranda siguió apoyando el esfuerzo publicista de Burke; colaboró en The Edinburg Review y en The Morning Chronicle; tra-

Ver María Teresa BerRuezo León, op. cit., pp. 38 y ss. 
bajó con José Maria de Antepara, según algunos autores de Guayaquil aunque Jimenez Codinach ${ }^{8}$ dice que era el «amigo mexicano" de Miranda, llegado en 1809. Miranda colaboró en la publicación de su obra South American Emancipation, una importantísima recopilación de documentos sobre la evolución del periodo prerrevolucionario en la América española, que se editó en 1810 y también con Antepara inició la publicación de El Colombiano, la primera revista en español de las muchas que se editaron en Londres a partir de esta fecha.

El Colombiano, dirigido nominalmente por Antepara en realidad fue obra de Miranda, que pretendió conseguir un importante instrumento de difusión y conocimiento mutuo entre los americanos que trabajaban por la emancipación. Solo se publicaron cinco números en el curso de 1810 y en ellos aparecieron comentarios y extractos de algunos artículos de El Español, que Blanco White empezaba a editar también en Londres.

"Quiso infundir entre los americanos, dice Berruezo ${ }^{9}$ el odio al tirano francés, personificado en la figura de Napoleón. Defendió bravamente los tres objetivos de su propaganda: Desprestigiar a la Junta Central y a la Regencia, presentándolas como ilegítimas e incapaces de gobernar España, y por tanto América. Comprometer al gobierno inglés, a través de las opiniones de algunos ingleses conocidos, que abogaban por las exigencias americanas de libertad $y$ buen gobierno. Finalmente el antibonapartismo, que impregnó sus páginas”.

Miranda sabía que las circunstancias políticas le eran adversas debido a la alianza anglo-española, pero al mismo tiempo su condición de luchador incansable hizo que no diera por perdida ningún ocasión. Por otra parte, nadie daba por seguro el desenlace de la guerra, tras la invasión de la Península y los éxitos iniciales de Napoleón. En el momento de la máxima expansión de los franceses Miranda se aplicó en alertar a los ingleses, pretendiendo movilizar sus esfuerzos para impedir que América cayera en poder de Napoleón.

\section{LLEGADA DE EMISARIOS Y PATRIOTAS}

Entre los primeros mexicanos que se localizan en Londres por aquellos años, además de Antepara Jiménez Codinach ${ }^{10}$ se refiere a Manuel Cortés,

\footnotetext{
8 Guadalupe Jimenez CODINACH, La Gran Bretaña y la Independencia de México. FCE. México, 1991, p. 276

9 Ver María Teresa BerRuezo Leon, op. cit., pp. 72 y ss.

10 De la misma obra, ver p. 276
} 
que al parecer era de orígen español y compañero de aventuras de Mariano Picornell. Cortés vivió en Londres, estuvo en contacto con otros mexicanos y viajó a Veracruz en diciembre de 1809. Antes de partir, dice Jiménez, presentó al Marqués del Apartado con Miranda. Cita incluso el texto de una carta de Cortés a Miranda (fechada 30 de diciembre de 1809), en la que le dice: "No ignorará usted el arrivo a ésta del marqués del Apartado de Mexico, con su hermano y un primo llamado Villaurrutea (sic por Villaurrutia); estos personajes son verdaderos marqueses criollos...".

Jiménez ha encontrado en las listas de llegadas a puertos ingleses la de la familia Fagoaga en 1809, que al parecer venian de la isla francesa de Guadalupe. Miranda los acogió con todo cariño y se dedicó a presentar al Marqués y acompañantes a distinguidas personalidades inglesas en Edimburgo y en Oxford. Pudo ser uno de los primeros viajes de los Fagoaga por Europa. A Francisco y a Villaurrutia los he localizado poco después en el Cádiz asediado por los franceses. Se sabe que regresaron a Londres algo más tarde, ya que hay un registro de llegada en 1811, «F. Fagoaga, de México, caballero particular", procedente de Guadalupe y algo más tarde el de "Wescenlao de Villaurrutia, caballero de México, acompañado de Servando Mier y Noriega, sacerdote de México". Estos últimos procedian de Cádiz.

En julio de 1810 la Junta de Caracas, que se había constituido en el mes de abril, decidió enviar una misión a Londres compuesta por Bolívar y Luis López Méndez como diputados y Andrés Bello que figuraba como Secretario. Sus objetivos eran los de granjearse la amistad de Inglaterra, ofrecer fidelidad al rey y a la monarquía española, expresar su odio a la Francia napoleónica y plantear la promesa de una alianza con la Gran Bretaña. Por su parte Bolívar pensaba obtener el auxilio británico en favor de la Junta y, sobre todo, entrar en relación con el General Miranda porque quería invitarlo a participar en la revolución.

La llegada de los diputados caraqueños reanimó el interés y el entusiasmo de Miranda que se puso al servicio de sus paisanos, les abrió todas las puertas, les acompañó a entrevistarse con políticos, periodistas y aristócratas, y se ocupó de organizar y facilitar tanto su estancia como su labor. Acabadas las conversaciones con el Marqués de Wellesley, que dio a sus contactos un tratamiento no oficial aunque cargado de promesas, Bolivar regresó en Septiembre a Venezuela, mientras Méndez y Bello se quedaban en Londres. Miranda, por su parte, decidió volver a Caracas a finales de ese mismo año. Al abandonar Miranda la ciudad de Londres en 1810, quedaron viviendo en su casa de Grafton Street los venezolanos Luis López Méndez y Andrés Bello, y con ellos también residía allí José María de Antepara.

En el verano de 1810 habían llegado tres agentes enviados por el gobierno de Buenos Aires: Matías Irigoyen, que regresó a Buenos Aires en 
1812, José Agustín Aguirre y Thomas Compton. También llegó Manuel Aniceto Padilla que actuaba con cierta autonomía personal ${ }^{11}$.

En mayo de 1811 se registró el arribo de Manuel Moreno y Tomás Guido, procedentes de Buenos Aires, quienes habian salido acompañando a Mariano Moreno, muerto durante la travesía. Llegaban en representación de la Junta Provisional Gubernativa de las Provincias del Río de la Plata, con la intención de plantear una serie de peticiones a Wellesley, Ministro de Asuntos Exteriores, quien muy pronto les transmitió que la política britanica se resumía en una idea principal: su país no intervendría en los asuntos internos de España y sus colonias.

Tomás Guido regresó muy pronto agobiado por dificultades económicas pero Manuel Moreno aprovechó su estancia en la capital británica para mantener vivo el recuerdo de su hermano y publicar algunas de sus obras. Envió a Buenos Aires informes muy negativos sobre la situación en Londres y en opinión de Berruezo "no gozó de muy buena reputación. Su conducta careció de moderación y diplomacia, por el contrario se comportó de forma airada e irreflexiva".

Moreno y Guido tomaron contacto con Walton, el periodista inglés que volverá a figurar repetidamente en todos los proyectos de campañas de propaganda y difusión independentista, concertando con él algunos acuerdos de publicación de noticias y artículos en The Morning Chronicle. Seguramente en los encuentros que mantenían con los demás americanos, sobre todo en la llamada "Logia Lautaro", establecieron muy buenas relaciones con Bello y López Méndez, consolidando asi el frente común que a partir de entonces se estableció entre las dos delegaciones presentes en la capital británica.

Moreno también entró en contacto con Blanco White, y entre ambos se anudó una estrecha amistad, ya que trataron de apoyarse mútuamente en sus intereses informativos. En 1811, El Español publicó una parte de la representación sobre el comercio libre de América escrita por Mariano Moreno en 1809. Finalmente Manuel se decidió a publicar una obra dedicada a ensalzar la figura de su hermano, en la que por otra parte recogió amplios resúmenes de su pensamiento y planteamientos políticos de actualidad.

Berruezo se refiere a ella y comenta su contenido ${ }^{12}$. Dice: "La obra no recogió deliberadamente la palabra independencia; tan sólo dio a entender

\footnotetext{
María Teresa BerRuezo León, op. cit., pp. 111 y ss.

12. El título final de la obra fue Vida y Memorias del Dr. Don Mariano Moreno, Secretario de la Junta de Buenos Ayres... con una idea de su revolución y de la de México, Caracas \&....por su hermano D. Manuel Moreno. Londres, 1812.
} 
que en América se estaban dando las bases legítimas que concedian el derecho a sus habitantes de rebelarse contra un mal gobierno. Moreno pensaba que España hubiera podido preservar la unión con América, evitando la violencia que asolaba a este continente. Debía haber existido una fraternal correspondencia de sus establecimientos, constituidos en gobiernos independientes y unidos a ella con los vinculos de una confederación».

Algo más tarde, en el curso del mes de junio, llegaron procedentes de Cádiz José de San Martín, Matías Zapiola y Carlos Maria de Alvear a los que acompañaban los mexicanos Fray Servando y Wescenlao Villaurrutia.

Los representantes venezolanos empezaron a sufrir graves carencias de carácter económico a partir de 1812, cuando los ejércitos realistas en América recuperaron posiciones y cayó el gobierno independiente. En 1812 el propio López Méndez pidió ayuda al gobierno inglés y después a Buenos Aires. Cada vez eran mejores y más amplias las relaciones entre venezolanos y argentinos.

También se encontraba en Londres el chileno Francisco Antonio Pinto, que se hizo muy amigo de Andrés Bello. Entre 1812 y 1814 tanto López Méndez como Bello pasaron grandes apuros económicos y estuvieron a punto de regresar a América, por lo que empezaron a tramitar su desplazamiento a Buenos Aires. Pero el regreso a España de Fernando VII y la implantación del absolutismo, que abria nuevas perspectivas de conseguir el apoyo inglés, les obligó a quedarse y a aguantar la situación.

Sin embargo como señala Berruezo ${ }^{13}$, "la postura de Gran Bretaña en el conflicto que enfrentaba a España y sus colonias, no iba a cambiar fácilmente. Desde 1812 Inglaterra actuaba como mediadora (por lo menos lo intentaba, aunque con nulo éxito) y continuaria apoyando esta politica hasta 1820 . Por esta razón los patriotas que llegaron a Londres buscando ayuda se encontraban con el recelo de las autoridades inglesas, que solian observarlos como a peligrosos revolucionarios". Aunque la administración y la opinión pública británica sentían una corriente de simpatía en favor de las exigencias de los patriotas, su alianza con España y su carácter de país mediador, aunque fuera en potencia, no les permitía hacer abiertamente nada que favoreciese a los insurgentes. Las esperanzas de los americanos de paso por Londres, a nivel diplomático o personal, chocaba con la política británica oficial.

13 María Teresa Berruezo León, op. cit., pp. 165 y ss. 


\section{SITUACIÓN EN 1814}

El regreso de Fernando a España, el final de las guerras en Europa y la captura de Napoleón, coincidieron en Gran Bretaña con una difícil situación económica, agravada por la guerra con los Estados Unidos y la necesidad de buscar nuevos mercados para sus productos allende los mares. Pero junto a la inestabilidad económica Inglaterra arrastraba un problema de carácter social. Miles de soldados recién desmovilizados pululaban por todo el país en busca de trabajo. Habian combatido a Napoleón y al regresar a su patria no encontraron ocupación. Muchos oficiales y soldados, tanto británicos como los nacionales de otros países que se encontraban en Inglaterra, optaron por alistarse en las filas de los patriotas para irse a América, en pos de aventuras y riquezas o para combatir contra la opresión. Unos por romanticismo y otros en busca de medios de vida, se sintieron atraídos por las historias y leyendas que circulaban por Europa sobre las enormes riquezas del continente americano.

La situación de los residentes americanos en Londres, por estas fechas, seguía siendo muy difícil. Para los venezolanos López Méndez y Bello las circunstancias eran las más adversas. Ya no existía el gobierno que los habia enviado a Gran Bretaña, los ejércitos realistas habían vencido a las tropas de Bolivar y en Nueva Granada los insurgentes se peleaban y enfrentaban entre sí. Uno de los líderes neogranadinos, Camilo Torres, en abril de 1814 se puso en contacto con el Príncipe Regente, invitándole a actuar en favor de la libertad americana. A continuación emitió credenciales a dos representantes suyos, Enrique Rodríguez y José María del Real, para que se trasladasen a Inglaterra.

En Gran Colombia, Bolivar, atento siempre a sus relaciones con el mundo exterior, tomó la decisión de enviar a Londres a Fernando Peñalver y a José María Vergara, aunque permanecieron poco tiempo en la ciudad. A Peñalver le sucedió Zea y Vergara tuvo que suspender su misión por razones de salud.

En Argentina la revolución se encontraba en un momento favorable que derivó pronto hacia enfrentamientos internos muy graves. Sin embargo, a finales de año se había decidido enviar a Londres a Manuel de Sarratea para gestionar la entrega de armas. Sarratea se convertiría muy pronto en una de las piezas clave en el puzzle de patriotas americanos dispuestos a conseguir el apoyo inglés. Sus actividades y planes se verían complicados algo después cuando, tras un cambio de gobierno en Buenos Aires, las nuevas autoridades decidieron enviar a Gran Bretaña a Belgrano y Rivadavia.

Por su parte, el Director Supremo de Chile, Bernardo O'Higgins también envió un representante a la corte inglesa, aprobando el nombramiento 
de Antonio José de Irisarri, con instrucciones para lograr el reconocimiento de la Independencia, un empréstito y un tratado amistoso.

En líneas generales, ninguno de tales "representantes" contaba con el respaldo de un gobierno estable. En esto no sólo influyó la inexperiencia de sus gobernantes, sino que los patriotas no habían acabado de asestar un golpe mortal a la ocupación realista. Estas circunstancias hicieron que los enviados americanos en Londres tuviesen que soportar condiciones muy difíciles. La incomprensión del gabinete británico, que no reconoció a sus gobiernos pretendidamente independientes, provocó en muchos un sentimiento de hondo desencanto.

Berruezo titula precisamente esta etapa, entre 1814 y 1820 , "La incomprensión y el desencanto" "14. En ella estudia con especial dedicación las actividades de algunos americanos, pero incluye una amplia noticia sobre las actividades de todos los demás. Uno de los personajes que analiza con mayor extensión es Andrés Bello, el americano que más años estuvo en Londres y a quien han dedicado amplios y múltiples estudios los historiadores latinoamericanos, especialmente Pedro Grases, español exiliado en Venezuela.

Bello tiene interés para este estudio, porque a lo largo de muchos años tuvo la ocasión de encontrarse con la mayoría de cuantos fueron pasando por Londres, pero también por sus contactos con los liberales españoles. Fue amigo, entre otros, de Blanco White ${ }^{15}$ que le ayudó en diversas ocasiones. Frecuentaba el Museo Británico y allí se encontró con otros estudiosos americanos como Fagoaga y españoles como Gallardo e incluso a veces con Puig Blanch. Las relaciones de Bello con el resto de los americanos fueron muy amplias. Compartió la amistad de Fray Servando Teresa de Mier con Blanco y entre ellos llegó a establecerse cierta complicidad intelectual. Solian verse y escribirse con frecuencia y esto ha permitido encontrar algunas cartas de interés.

El seguimiento de Bello ${ }^{16}$ me ha llevado a conocer algunos documentos que lo relacionan con José María Fagoaga, primo del Marqués del Apartado y de Francisco Fagoaga, miembros los tres de una de las familias criollas más

\footnotetext{
14 Es la tercera parte de su obra, e incluye tres capítulos fundamentales para este trabajo, ya que cubren la etapa que va desde 1814 a 1820 .

15 El estudio más reciente sobre Blanco White es de Manuel Moreno Alonso, Blanco White, la obsesión de España. Ediciones Alfar. Sevilla, 1998. Moreno Alonso tiene una amplia obra de investigación sobre la época y las circunstancias de la vida política y social en el Londres de esos años.

16 Sobre Bello existe una amplia bibliografía hispano americana. Es de gran interés la obra Bello y Londres, que recoge las actas del Segundo Congreso del Bicentenario, celebrado en Caracas en 1980 .
} 
importantes y decisivas en el proceso de Independencia de Nueva España y, como veremos más adelante, quizá el núcleo fundamental del apoyo mexicano a la expedición de Mina. Berruezo ${ }^{17}$ cuenta los contactos de Bello con José María Fagoaga. Se refiere a un momento, en el verano de 1816, cuando Bello pasó por otra etapa de graves apuros económicos y Blanco White encontró para ayudarle un nuevo apoyo personal: Se trataba de William Hamilton, el Subsecretario de Exteriores, que había estado ayudando a Mina durante varios meses. Hamilton necesitaba alguien a quien confiar la educación de sus hijos y Blanco le recomendó a Bello. Según Berruezo, "será entonces cuando conozca al español José María Fagoaga (lo era de nacimiento pero ha destacado en la historia de México como miembro de una acrisolada familia de criollos), que había estado preso por su colaboración con los insurgentes y había sido expatriado en 1815. Expulsado de Nueva España por Calleja, debió llegar a la península a finales de ese año, aunque aquí se pierde su pista hasta que apareció en Londres poco después".

“(Fagoaga), era un partidario del gobierno monárquico en América con un príncipe de la Familia Real y apoyaba todas las reformas introducidas por las Cortes. El gobierno absolutista de Fernando VII no le perdonó su "liberalismo" y por ello fue perseguido. Fagoaga era también un hombre educado y con inquietudes culturales. Era lógico que su encuentro con Bello resultara inevitable», dice Berruezo. "El español estaba al corriente de las penurias del venezolano y, por supuesto, conocía su vasta formación y dominio de la lengua. Fagoaga trabó amistad con el cirujano inglés William Blair, quien además de su carrera en la medicina era un hombre de profundas convicciones cristiano. evangélicas, que deseaba dar a conocer a la humanidad...Todo sucedió en una mañana de julio de 1816, en la que Fagoaga se encontró con Mr. Blair".

Lo recuerda el propio Fagoaga: "Esta mañana en el Museo, me preguntó Mr.Blair, del no 69 Great Russell Square, si conocía algún español capaz de corregir una traducción española de la Biblia i acordándome de $\mathrm{Vd}$ le dije que conocía uno que, por el perfecto conocimiento de su lengua, y su buen gusto en literatura, me parecia mui a propósito; pero que ignoraba si sus ocupaciones le permitían emprender su trabajo" ${ }^{18}$. Añade $\mathrm{Be}$ rruezo: «La Biblioteca Británica fue un lugar de cita para los emigrados españoles que llegaron a partir de 1814 y 1815 . Hombres de la talla de Antoni Puigblanch y Bartolomé José Gallardo acudieron con asiduidad a su sala de lectura. Allí es donde coincidieron con Bello, iniciándose una amistad personal y una relación intelectual»» ${ }^{19}$.

\footnotetext{
17 María Teresa BerRuezo LEON, op. cit., p. 175.

18 La carta de Fagoaga, fechada el 31 de julio de 1816, está reproducida en Miguel Luis Amunategui, Vida de Don Andrés Bello. Santiago, 1882.

19 María Teresa BerRuezo León, op. cit., p. 181.
} 
Bello tuvo un amistoso y provechoso contacto con Manuel Sarratea, el argentino que había llegado a Londres en 1814. Antes de salir de Buenos Aires Sarratea ya conocía la situación de Bello y López Méndez, por lo que consiguió de su gobierno la decisión de apoyarles, convencido de que le serían utilísimos para facilitar sus gestiones ante el gobierno inglés. Nada más llegar les asignó unos ingresos de 150 libras esterlinas al año, cuyo pago se inició el 1 de junio de 1814. Manuel de Sarratea tuvo en Londres una actividad importante, ya que fue el responsable de la puesta en marcha de una amplia labor de propaganda, la segunda en muy poco tiempo, que corrió nuevamente a cargo de William Walton, el inglés que había escrito algunas obras dedicadas a la situación en América ${ }^{20}$. Sarratea aparece con relativa frecuencia en la correspondencia del Embajador español en Londres, que trataba de seguir lo más cerca posible todos sus manejos.

Berruezo ${ }^{21}$ dice: "La participación de Sarratea como colaborador (de Walton) es palpable, porque el escritor recogió parte de sus instrucciones y parte de sus ideas monárquicas personales. Sarratea tenía como meta de sus gestiones conseguir la mediación inglesa para el inicio de conversaciones con España y lograr que se reconociera la autonomía del gobierno de El Plata. Y en cuanto al sistema a implantar se inclinó por la monarquía y desconfió del régimen republicano. Walton hizo figurar estos objetivos de Sarratea como los pilares fundamentales que se apuntaban en su obra, para acabar con la guerra entre España y sus colonias».

Los servicios propagandísticos de Walton resultaron muy útiles a los objetivos de Sarratea, pero no iban a ser los únicos en la campaña proindependentista. La llegada de Del Real a Londres y la estancia indefinida de López Méndez determinó a las tres delegaciones, venezolana, neogranadina y rioplatense, a actuar de forma conjunta. Del Real, en carta al Presidente de las Provincias Unidas de la Nueva Granada, el 1 de febrero de 1815 (unas semanas antes de la llegada de Mina a Bristol), escribía: "... en unión con el diputado de Buenos Aires (Sarratea) solicitamos a Mr. Guillermo Walton, hombre bastante instruido, adicto a nuestra independencia y que ha publicado varios papeles en favor de la América, para que se encargase de insertarlos en el Morning Chronicle, mediante la oferta de su editor...".

\footnotetext{
20 William WALTON, escritor y periodista, de quien Fray Servando Teresa de Mier tenia una pésima opinion, escribió Present state of the Spanish colonies. Londres, 1810 y An Exposé of the dissentions of Spanish America. Londres, 1814.

21 María Teresa Berruezo Leon, op. cit., pp. 183 y ss.
} 
Lo que Berruezo desconoce, pero que Fray Servando se ocupará de recordar ${ }^{22}$, es el profundo enfado que le corroía por culpa de Mr. Walton, al que acusaba repetidamente de haberse apropiado de sus ideas, documentos, comentarios y opiniones.

La campaña de Walton en el Morning Chronicle se inició el día 11 de febrero de 1815. Berruezo comenta: «El verano de 1815 continuó siendo muy prolífico en noticias sobre el continente americano. Las fuentes de información fueron principalmente las gacetas, papeles y cartas venidas de ultramar. Hubo comentarios acerca de lo que estaba sucediendo en las Provincias Unidas, en Venezuela, Perú y Cartagena". Los escritos de Walton fueron ganando fuerza en su intento de pintar un continente totalmente volcado por acabar con el sometimiento a España. Los tres enviados americanos que respaldaban el contenido de estos artículos debieron haber sentido una gran satisfacción al leer su mensaje triunfalista. El periodista llegó a escribir que «el fantasma de Fernando VII estaba completamente destruído y que todo hablaba del derrumbamiento del poder español". La campaña subvencionada por Sarratea, López Méndez y Del Real no podía ir mejor y prosiguió en esa misma línea con la entrada del otoño de 1815.

Este era el clima emocional y ambiental que se vivía en Londres durante la época en la que Mina permaneció en esa ciudad. En los medios liberales y patriotas los años 1815 y 1816 representan el momento de máxima expectación, de mejores proyectos, de posibilidades más prometedoras, con respecto a la postura británica y su posible implicación en el proceso de apoyo a los insurgentes.

Bello también colaboró (al igual que lo había hecho a lo largo de 1812 con Fray Servando Teresa de Mier), con Manuel Palacio Fajardo, que acababa de llegar de París. El 7 de febrero de 1815 Bello y Palacio redactaron juntos un informe dirigido al Presidente de Cartagena. La gran obra de Palacio, publicada en Londres a mediados de 1817, fue Outline of the revolution in Spanish America ${ }^{23}$, cuyo rápido éxito motivó la aparición de nuevas ediciones y traducciones en Estados Unidos, Francia y Alemania. Durante algún tiempo, el hecho de que se publicara con la

22 Fray Servando Teresa DE MIER, "Carta a Srs. P. y A", escrita en Galveston, que se encuentra entre los papeles de su "Causa", en Hernández y Dávalos.

23 La primera edición, publicada en Londres en 1817 aparecía firmada "by a South American» y durante muchos años se pensó seriamente que habia sido escrita por Bello. Berruezo le dedica amplio espacio y recoge la revelación final de que su autor había sido Palacio Fajardo. Bello, como resultó evidente, colaboró ampliamente con el autor. 
firma de "un sudamericano», contribuyó a pensar que había sido escrita por Bello.

Juan Garcia del Rio, neogranadino, que habia llegado a Londres en 1814 como secretario de legación a las órdenes de José María del Real, escribió una autobiografía al regresar a América y en ella recogió las impresiones sobre sus dos periodos de estancia en Londres. Correspondiente a su primer viaje, había regresado a su tierra en 1818, es interesante repasar este texto en el que se refiere a cuantos había conocido: "Muchos americanos distinguidos, a quienes tuve la honra de tratar en esos años en Inglaterra: los Srs. Fagoaga, Alamán y Villaurrutia, procedentes de México; Sarratea, Belgrano y Rivadavia, de Buenos Aires; López Méndez y Bello de Caracas; Francisco Antonio Pinto e Irisarri, de Chile; Joaquín Rafael Mosquera, Zea y Manuel José Hurtado, conocen ese periodo de mi vida" ${ }^{24}$.

A finales de 1814 y comienzos de 1815 desembarcaron en Inglaterra varios comisionados neogranadinos que venían de Francia, donde no habían conseguido ninguna respuesta favorable a sus peticiones de apoyo a la insurrección americana. Fueron Manuel Palacio Fajardo, Agustín Gutiérrez Moreno y Francisco Antonio Zea. Gutiérrez Moreno había ido a Francia a comprar fusiles y a su llegada a Londres conoció a Irisarri, con quien intimó y a quien serviría años más adelante, durante la segunda estancia de Irisarre en Gran Bretaña.

Zea, uno de los americanos más cultos de la época, había estudiado leyes, economía política, historia y literatura, sin olvidar la botánica. Fue ayudante de Mutis y estuvo pensionado por el gobierno español, hasta que culpado de simpatía por los insurgentes de Nueva Granada fue desterrado a Madrid. Poco después se le envió a París, al filo del fin de siglo, en una misión científica. Allí conoció a Miranda. Poco después regresó a Madrid, y en 1805 fue director del Jardín Botánico. "Simpatizante del partido afrancesado, estaba convencido de que Francia ayudaría a liberar las colonias españolas", dice Berruezo. En la época de José I fue diputado en las Cortes de Bayona, director del Ministerio del Interior y jefe político de Málaga. Huyó a París, tras la derrota de Napoleón y de allí pasó a Londres, camino de América. En este primer periodo de su estancia en Gran Bretaña permaneció unos meses y en abril de 1815 embarcó rumbo a las Antillas.

24 Juan Garcia del Rio y Diego PAROISSIEN, Justificación de la conducta pública seguida por Don Juan García del Río y Don Diego Paroissien, Ex Ministros plenipotenciarios del Gobierno del Perú en las Cortes de Europa. Londres, 1825. La frase reproducida está en Domingo Amunátegui Solar. Recuerdos biográficos. Santiago de Chile, 1938, p. 55. 
La situación política no era muy favorable porque Napoleón había reaparecido en Paris dispuesto a reconstruir el Imperio. Este hecho acaparó el interés de Gran Bretaña, cuyo mayor deseo se cifraba en la derrota del francés. Cuando las fuerzas de Napoleón fueron aniquiladas en Waterloo desapareció aquel temor aunque no del todo. Durante bastante tiempo se habló en Londres de la existencia de un «partido napoleónico que al parecer estaba formado por el grupo de la nobleza más radical». Por otra parte las victorias realistas en la América española supusieron un retroceso general de los patriotas en todos los frentes lo que dificultó muy pronto las actividades de los americanos en Londres.

García del Río ${ }^{25}$ en sus "Memorias» dice que "trabajamos cuanto podíamos para ganar prosélitos a nuestra causa". Entre los métodos que utilizaron, señala Berruezo, figuró el intento de cultivar la amistad de personas que pudieran influir o ayudar de alguna forma a la independencia y también "estimulando a algunos miembros del Parlamento a que hicieran mociones a favor de la América; y preparando y haciendo publicar escritos para instruir al pueblo inglés del estado de nuestros negocios, manifestando la justicia que los asistía y las ventajas que nuestro triunfo reportaria al comercio de la Gran Bretaña».

De la posición inglesa en esos años es fiel reflejo la correspondencia de José María del Real ${ }^{26}$ con el Presidente de las Provincias Unidas de Nueva Granada. En sus primeros escritos contaba sus contactos con Sarratea, quien le había adelantado que Inglaterra no apoyaría abiertamente la emancipación y que no podría ser recibido como diplomático por no pertenecer a un país reconocido. Más tarde, cuando intentó ser recibido por un ministro británico tuvo que buscar el apoyo de López Méndez y a finales de año, el 7 de diciembre de 1814, reportaba que «por su mediación había conseguido una entrevista con uno de los ministros, muy afecto a América". Acompañaba las cartas con recortes de periódicos y entre ellos una Gaceta ministerial de Buenos Aires. En ella se refería el envio a España de una diputación (Rivadavia y Belgrano) con instrucciones para conceder la supremacia a España, bajo condiciones que el gobierno español no admitiría. También informaba de la llegada a Londres de Zea y Palacio, con quienes logró intimar rápidamente.

25 Juan GARCIA DEL RIO ... op. cit.

26 Ver Sergio EliAS ORtiz, Doctor José Maria del Real. jurisconsulto y diplomático. Prócer de la Independencia de Colombia. Bogotá, 1969. 
Palacio Fajardo había llegado a Londres en enero de 1815 , con la intención de aprovechar el tiempo de que disponia. Pronto entró en contacto con el grupo de americanos, pero también con los españoles liberales de Londres. Fue a ver a Sarratea, con el que había mantenido correspondencia desde París. Conoció a Andrés Bello y preparó con él una «Memoria» que Palacio envió a su gobierno. Bello, que comprendió la importancia del libro que preparaba Palacio, se ofreció para colaborar con él, lo que hizo sin la menor limitación.

Berruezo ${ }^{27}$ dice que "desde su llegada hasta la publicación de su obra pasaron casi dos años. En este tiempo pudo observar el enfriamiento de los escritos de William Walton en el Morning Chronicle (¿coincidió ese enfriamiento con la ausencia de Mier, que se había ido con Mina a Estados Unidos?); la oposición de la empresa conservadora a la intervención británica en el conflicto americano, así como la decisión británica de permanecer neutral debido a su alianza con España. En 1816 los partes y las Gacetas americanas informaban de los avances del ejército realista. La situación no mejoraba en absoluto, complicándose con la total ignorancia que el pueblo británico tenia sobre aquel continente».

Al referirse a los representantes del llamado "Cono sur americano", Berruezo señala que dentro de ese área las Provincias Unidas del Río de la Plata tuvieron en Londres la representación más numerosa durante el periodo de 1814 a 1818. A Manuel Sarratea se incorporaron un año después Belgrano y Rivadavia. Chile, por su parte envió a José Antonio Alvarez Condarco, que llegó a mediados de 1817. En Londres ya estaba Irisarri, expulsado de Chile por los Carrera y muy pronto se convirtió en el primer diplomático chileno. Sin embargo, las relaciones entre ellos no fueron cordiales. Entre Sarratea e Irisarri se planteó un grave enfrentamiento como consecuencia de las posturas del primero. Sarratea habia empezado a actuar antes de la llegada de Belgrano y Rivadavia y su primera medida fue dirigirse a Fernando VII, intentando congraciar al monarca con las nuevas autoridades de aquellas provincias.

En su "Exposición", Sarratea se refería al estado en que se hallaba el país, a la necesaria mediación inglesa para llegar a una solución pacífica y a la fidelidad de sus habitantes. Envió este mensaje al ministro español Cevallos a través de Cabarrús, "un vividor que le ayudaba en sus planes pacificadores", como dice Berruezo. Al llegar los nuevos comisionados, Sarratea se enteró por ellos de que las Provincias Unidas nunca entrarían en convenios con España si no contaban con la protección británica.

27 María Teresa Berruezo León, op. cit., pp. 196 y ss. 
Es importante saber que poco después de la llegada de Rivadavia y Belgrano a Londres en mayo de 1815, casi coincidente con el arribo de Mina, tuvo lugar la derrota de Napoleón en Waterloo, lo que significaba una rotunda victoria de la legitimidad, el ultraconservadurismo y la monarquía sobre el republicanismo o la revolución. El cuadro político europeo se presentaba bastante adverso para el logro de los objetivos de los americanos más radicales.

Sarratea, enfadado por la llegada de los nuevos enviados argentinos, insistió en sus propósitos y en el proyecto de instaurar una monarquía en las Provincias Unidas en la persona de un príncipe español, al parecer Francisco de Paula. Se dice que con este propósito utilizó al conde de Cabarrús como agente para entrar en contacto con Carlos IV y transmitirle su plan. Al parecer, convenció a sus compañeros y el propio Belgrano redactó un proyecto de Constitución, basado en las ideas de Bentham. Según algunas fuentes, Cabarrús se desplazó a Roma, donde estaba Carlos IV, que rechazó este plan. La noticia de la derrota de Napoleón debió pesar en la respuesta negativa del ex monarca, cuyo deseo era mantener las mejores relaciones con las potencias vencedoras. No hubo manera de convencerle en favor del proyecto y Cabarrús regresó a Londres con el fracaso de su misión y una larga lista de gastos cuyo pago exigió de inmediato. Rivadavia y Belgrano pidieron a Sarratea que Cabarrús presentase pruebas documentales de sus cuentas, lo que se convirtió en un nuevo foco de conflicto entre ellos.

Berruezo se refiere también a Aimé Bonpland ${ }^{28}$ que había acompañado a Humboldt en sus viajes por América, y que, aunque residia en París, viajaba con frecuencia a Londres. En unas memorias tituladas "Londres, cuartel general europeo de los patriotas de la emancipación americana", Bonpland escribió: “En 1814, 1815 y 1816 hice varios viajes a Londres con el objeto de hacer mis relaciones con Bolivar más frecuentes y más útiles a la America. Entonces conocí particularmente a los Srs Belgrano, Sarratea y Rivadavia y la amistad de estos señores reunida a los desastres que sufrió el General Libertador de Venezuela, hicieron mudar mis proyectos y gané las aguas del Plata". Bonpland, tras las derrotas de Bolívar en 1815 y 1816, había puesto su confianza en la independencia americana empezando por el Río de la Plata. Esta convicción le llevó a animar a Rivadavia para que emprendiera viaje a París aunque éste, a petición de Cevallos, prefirió adelantar su viaje a Madrid. A partir de 1816 en París, Bonpland, Humboldt, el general Laffayette y monseñor

28 Ver Archivo de Bonpland IV: Londres, cuartel general europeo de los patriotas de la emancipación americana. Se encuentra en la Universidad de Oxford, Inglaterra. 
De Pradt estaban tratando de constituir un núcleo político-intelectual en favor de la independencia americana.

\section{GRAN BRETAÑA Y LA NUEVA ESPAÑA}

Se ha publicado en México una obra fundamental para el conocimiento del papel que Inglaterra jugó, durante muchos años (1808-1821), en el proceso de surgimiento y desarrollo del movimiento en favor de la emancipación de Nueva España. Su autora, Guadalupe Jiménez Codinach se propone desvelar el por qué de la falta de textos y materiales que expliquen el interés y la inclinación inglesa sobre México y centra su estudio en varios grandes ejes: La información, la política, el comercio y las conspiraciones ${ }^{29}$.

En cuanto a información, se refiere a los informes de inteligencia, las descripciones de viajeros y comerciantes, pero también a los libros y folletos, la prensa y la opinión pública. Recoge gran cantidad de materiales riquísimos y llenos de interés que permiten acercarse a la compleja realidad británica de la época. Respecto de la política se pregunta si Gran Bretaña fue realmente un instrumento de liberación, en la difícil coyuntura de la segunda década del XIX, una vez que se planteó el acuerdo con España para luchar contra Napoleón. Analiza las distintas etapas de desarrollo del conflicto generalizado y el papel que representaba Nueva España en la coyuntura internacional. La importancia del comercio inglés en el mundo y el juego de los intereses en el ámbito atlántico y las relaciones de Gran Bretaña con España, Estados Unidos y Nueva España, es el objeto de la tercera parte de esta obra, en la que estudia a fondo el papel que desempeñaron algunas casas comerciales y en especial la Gordon y Murphy, establecida en México, Cádiz y Londres. Finalmente la especial dedicación al tema de las conspiraciones en Londres, "cuartel general de los patriotas latinoamericanos", me ha deparado una de las más gratas y emocionantes sorpresas de los últimos años. Nada menos que la de encontrar una importante investigación, en los archivos ingleses y norteamericanos, en los que Jiménez Codinach ha seguido la pista de Xavier Mina, al que ha tomado como "caso de estudio", para explicar la importancia que los ingleses (pero también los norteamericanos) concedían a la liberación de las provincias españolas de América y en especial a Nueva España.

29 Guadalupe JIMENNEZ CODINACH, op. cit. 
En su presentación, Jiménez Codinach plantea dos hechos obvios:

“1. La Gran Bretaña de fines del siglo XVIII y principios del XIX estaba en vias de convertirse en la primera potencia industrial en el mundo. Su fuerza se apoyaba, entre otras cosas, en su flota marítima y en su industria. Los británicos necesitaban rutas comerciales, materias primas, mercados y particularmente plata y oro para lubricar su comercio y su hegemonía política.

2. Al finalizar el siglo XVIII México era el primer productor mundial de plata, además de estar considerado una fuente potencialmente rica en materias primas y un mercado de consumo de productos manufacturados ingleses". Por tanto, se pregunta Jiménez Codinach, ¿cómo era posible que ambos países no tuvieran relación alguna durante un momento tan decisivo?

\section{MEXICANOS EN GRAN BRETAÑA}

Frente a quienes opinan que la política británica en la época de las revoluciones reaccionaba ante los acontecimientos inmediatos y no perseguía una meta de largo alcance, de tal manera que lo inesperado, una repentina alianza o una declaración de guerra, el éxito o fracaso de una determinada batalla, influian en la política mucho más que una planeación calculada y a largo plazo, Jiménez Codinach muestra en su obra que la política británica, aunque respondía a coyunturas internacionales, no procedía casualmente. En realidad, los dirigentes británicos tenian muy en cuenta la expansión de los intereses mercantiles y financieros de sus súbditos, en una época en la que Inglaterra se habia convertido en el eje de la revolución industrial.

Para Inglaterra la América española y Nueva España especialmente, representaban una fuente de materias primas pero también un mercado potencial abierto a las manufacturas británicas: algodón, ferretería, papel, porcelana, muebles y armas que tan difícil posibilidad de venta encontraban en un continente dominado y en ocasiones cerrado a cal y canto por Napoleón, sobre todo a partir de 1806. Inglaterra no podia absorber sus excedentes de producción. Dice Jiménez Codinach: "La política británica hacia la emancipación de las colonias españolas no se puede separar del proceso de la Revolución industrial en Inglaterra ni su rivalidad económica con Francia, los Estados Unidos y otros países. Ni se le puede ver sin tomar en consideración la guerra política y diplomática que se había declarado contra la Francia napoleónica».

$Y$ aunque es cierto que la presencia y actuaciones inglesas en la América española fue permanente y constante a partir del siglo XVII, el desarrollo 
de la conciencia autonomista local, las contradicciones de la política central y finalmente la decadencia del poder metroplitano, así como los múltiples levantamientos criollos frente a las autoridades realistas, favorecieron las pretensiones inglesas y permitieron a Inglaterra y a sus comerciantes ocupar un vacío de presencia, negocios, relaciones y contactos en los mercados y centros de poder del continente europeo, pero también del continente hispano americano.

Por ejemplo, cuando por medio del Tratado de Utrecht en 1713, Inglaterra adquirió el privilegio del Asiento, el barco que se enviaba anualmente a la América española con esclavos, también transportaba mercancías y manufacturas. A lo largo de muchas décadas la marina inglesa, situada permanentemente en el Caribe, mantenia, sostenía y extendía los intereses británicos por toda la zona. Esa presencia, penetración y dominio mas o menos embozados, se agudizó y profundizó después de la cesión de las Floridas a los ingleses por el tratado de 1763. Al establecerse en Jamaica y en las Floridas, a lo largo del siglo XVIII, los ingleses se encontraron que el camino hacia México quedaba abierto sin mayores dificultades. Jiménez, que ha estudiado con todo detalle las relaciones entre novohispanos y británicos, apunta y reseña los lazos e incluso «las ligas secretas» que existían entre los comerciantes de Veracruz y las casas de comercio de Inglaterra, especialmente a partir de 1797.

En los primeros años de insurgencia americana la inexistencia en Nueva España de una Junta o estructura política similar, que se plantease la representación generalizada de los grupos que pretendían la emancipación, impidió la presencia de delegados, revestidos de cierta oficialidad, en la ciudad de Londres junto con los demás representantes americanos.

Berruezo ${ }^{30}$ sólo se refiere a Fray Servando Teresa de Mier, que llegó a Londres en 1811, fundamentalmente para comentar y estudiar su famosa Historia de la Revolución de Nueva España y más adelante, en torno a 1816, da cuenta de la presencia en Londres de José María Fagoaga cuando narra su encuentro y apoyo económico a Bello. Sin embargo, la presencia de mexicanos en Londres fue mucho más numerosa e importante. Me voy a referir exclusivamente a los años iniciales, entre 1810 y 1820 , porque a partir de 1823 el México independiente sería el primer país que lograse el reconocimiento oficial británico y el primero en acreditar a sus representantes oficiales.

30 María Teresa Berruezo León, op. cit., pp. 128 y ss. 
Viene a llenar este hueco historiográfico la obra de Jiménez Codinach ${ }^{31}$. Al recorrer sus páginas aparecen numerosos ecos de encuentros, relaciones, contactos y presencias mexicanas, tanto en Inglaterra como en otros paises europeos. Londres debió ser lugar de preferencia para los criollos acaudalados en viaje por Europa desde finales del siglo XVIII. Con respecto a sus relaciones políticas Jiménez cita la propuesta que en 1785 elaboraron tres miembros de la aristocracia criolla novohispana, el Conde de Torre de Cosio, el conde de Santiago y el marqués de Guardiola, y que se envió al rey de Inglaterra solicitando ayuda para liberar a Nueva España. Los firmantes de la proposición eran miembros de tres conocidas familias mexicanas, relacionadas entre sí por la amistad y los matrimonios, poseedores de grandes fortunas acumuladas en el comercio, la agricultura y la minería.

En sus notas, Jiménez señala que la hija del conde de Torre Cosío estaba casada con Juan José de Fagoaga, Marqués del Apartado, abuelo del Marqués del Apartado que apareció por Londres en las primeras décadas del siglo. Precisamente la mención del Marqués del Apartado es importante porque forma parte de una amplia familia, a la que se suele denominar "los Fagoaga", que desempeñó un papel decisivo en los proyectos de emancipación y autonomía mexicanos, así como en los planes de intervención militar de Xavier Mina. Menciones a la familia Fagoaga aparecen en todas las historias de la Independencia, pero también en las obras publicadas recientemente que se refieren a la nobleza mexicana de los siglos $X V 111$ y $\times 1{ }^{32}$.

Jiménez Codinach ${ }^{33}$ en un apartado dedicado a recoger las noticias de los mexicanos en Londres cita al Marques del Apartado en 1809, así como a otros familiares suyos, en una carta de Manuel Cortés Campomanes (español y colaborador de Mariano Picornell en la conspiración de San Blas en Madrid el año de 1796) y que expulsado de España se refugió en Venezuela de donde pasó a la isla de Guadalupe, para encontrarse finalmente con Miranda en Londres. Cortés, en carta a Miranda, fechada el 30 de diciembre de 1809, le dice: “No ignorará usted el arrivo a ésta del marqués del Apartado de Mexico con su hermano y un primo llamado Villaurrutea (sic por Villaurrutia); estos personajes son verdaderos marqueses criollos...».

Guadalupe JIMÉNEZ CODINACH, op. cit.

32 La obra más importante es la de Doris M. LADD, La nobleza mexicana en la época de la independencia. Fondo de Cultura Económica. México, 1984. Contiene una amiplisima bibliografia sobre el tema.

33 Guadalupe JIMENEZ CODINACH, op. cit, pp. 276 y ss. Manuel Cortés había sido colaborador de Mariano Picornell en la conspiración de San Blas, en Madrid, el año 1796. Cortés siguió sus aventuras por distintos puertos del Caribe, al igual que Picornell. 
No era la primera vez que los mexicanos viajaban por el Viejo continente, y los tres habian estado muy activos en los sucesos de Nueva España en 1808. Jacobo Villaurrutia, el padre de Wescenlao, había participado en el enfrentamiento de los criollos y el Cabildo con el virrey Iturrigaray y un primo de ellos, José María Fagoaga, saldria elegido en los primeros comicios municipales que se celebraron en la ciudad de México.

He podido revisar los testimonios de Fray Servando Teresa de Mier sobre su estancia en Londres y las actividades a que se dedicó. Biógrafos y críticos han publicado algunos trabajos y comentarios sobre el tema ${ }^{34}$. De entrada se puede añadir que una de las primeras ocupaciones de los mexicanos recién llegados fue el contacto y la comunicación con los demás americanos, con los que promovieron el desarrollo de la famosa "Logia Lautaro o de los Caballeros Racionales". También participaron, junto con otros americanos y con los liberales españoles, en las actividades del llamado "Cuartel General de Patriotas Americanos".

La "Logia Lautaro o de los Caballeros Racionales» ${ }^{35}$, cuya categoría masónica ha sido objeto de una amplia crítica, tanto a favor como en contra, fue instalada inicialmente en Londres por Miranda y desde allí se extendió por distintas ciudades de América y España. En Cádiz la habia establecido Carlos Alvear y en ella entraron Villaurrutia y San Martín, así como Mier, cuando éste llegó a Cádiz a comienzos de 1811. En la logia de Londres, además de Mier y Villaurrutia, también se inscribieron el Marqués del Apartado y su hermano Francisco.

El árbol genealógico de los Fagoaga es el siguiente ${ }^{36}$.

1. Coronel Francisco Manuel Fagoaga y Arosqueta (Primer Marqués del Apartado). Casado con Magdalena Villaurrutia.

Hijos: Josefa Maria, casada con su primo José Maria. José Francisco Fagoaga, Segundo Marqués del Apartado. Francisco Fagoaga.

it Sobre Fray Servando, conviene ver los papeles de su "Causa”, en Hernández y Dávalos, asi como las obras de O'Gorman, Miquel i Vergés, etc.

35 La logia Lautaro ha dado lugar a una amplia bibiografia. Entre los historiadores españoles le ha dedicado amplio interés Ferrer BENIMELLI: "Cádiz y las llamadas "logias" Lautaro o Caballeros Racionales". En III Encuentro de la llustración al Romanticismo. Cádiz, 1987, asi como en "Bolivar y la masoneria», en Revista de Indias, ${ }^{\circ}$ 172. Madrid, 1983. También se debe ver Antonio $R$. Zuniga, La logia Lautaro y la independencia de Arnérica. Buenos Aires, 1922.

36 Doris M. LADD, La nobleza mexicana en la época de la Independencia. FCE. México, 1984, p. 275. 
2. José Francisco Fagoaga Villaurrutia, Segundo Marques del Apartado Fue diputado a Cortes. Murió en París en 1840.

3. Francisco Fagoaga Villaurrutia. Nacido en 1788, fue diputado a Cortes, alcalde de México y Ministro de Relaciones, además de Senador de la República. Murió en 1851. Era casi de la misma edad que Mina.

4. El sobrino Wenceslao de Villaurrutia, hijo de Jacobo de Villaurrutia, fundador de El Diario de México, oidor y miembro de la Suprema Corte de México. Jacobo tuvo otro hijo: Antonio de Villaurrutia, Oidor de Guadalajara.

5. El sobrino José María Fagoaga y Leizauer, nacido en Rentería (España) el año 1764. Fue diputado a Cortes, Diputado provincial de México, miembro de la Suprema Junta con Iturbide y O'Donojú y posteriormente diputado del Congreso de México. Murió el año de 1837.

Jiménez Codinach ${ }^{37}$ se queja, con toda razón, del desconocimiento existente, hasta que llevó a cabo sus investigaciones en los archivos europeos, del papel que el Marqués del Apartado y su familia habian desempeñado en relación con la expedición de Mina.

A continuación establece:

1. En las listas de personas residentes en México, a quienes se enviaba «El Colombiano», la revista de Miranda, figuraban entre otros, Jacobo Villa Urrutia, José Mariano Almanza (quien más tarde aparecerá en los contactos de Mina en Veracruz), José Maria Fagoaga y José Ignacio Pabón, también de Veracruz.

2. Carlos María de Bustamante, en sus obras histórico críticas, ofrece pruebas del temprano interés de los Fagoaga por apoyar el movimiento insurgente. Al parecer el primer manifiesto de la llamada Junta Suprema de la Nación, publicado en el aniversario del 16 de septiembre de 1810, fue llevado a Londres por el Marques del Apartado, quien se lo entregó en mano a Miranda para su publicación.

3. Cita referencias documentales del encuentro de Santa María con Almanza en Veracruz en 1817, las cartas de Onís a Apodaca, las cartas de Mier en Estados Unidos y después de su prisión por los realistas, y los textos de Alamán, que dan cuenta de la estancia del Marqués y de su hermano en Europa por estos años.

4. La prueba que Jiménez Codinach califica de decisiva, como comprobación del papel jugado por los Fagoaga en la preparación de la ex-

3) Guadalupe JIMENEZ CODINACH, op. cit., p. 280. 
pedición de Mina, es el manuscrito, sin fecha y sin terminar, que encontró en los papeles de sir Robert Wilson, en los archivos ingleses y que, al parecer, circuló entre influyentes casas comerciales inglesas y ciertos individuos, para convencerles de que apoyasen una expedición a México.

5. Mier, Alamán, los Fagoaga y Villaurrutia, dice Jiménez Codinach, eran también miembros del "Cuartel General de Patriotas Americanos en Londres", la organización de la que existen amplias noticias gracias a la documentación del "Archivo Aimé Bonpland" ${ }^{38}$.

Ladd ${ }^{39}$ se refiere a los contactos internacionales de las familias mexicanas, y en lo que respecta a los Fagoaga dice que «los jóvenes Fagoaga idearon su propia conspiración liberal internacional, estableciendo a miembros de su familia en Londres, Cádiz, Madrid y Ciudad de México". Sobre los Villaurrutia, emparentados con los Fagoaga, señala que era una familia cosmopolita, con contactos en Guatemala, Bolivia, el Caribe y España. Charles Hale y David Brading dicen que las familias y grupos de familias de los Fagoaga, Villaurrutia y Castañiza eran las más interesantes de aquellos momentos. También han escrito sobre este tema Kizca, Tutino y otros autores ${ }^{40}$.

El primero en tener una actuación destacada fue Jacobo Villaurrutia, promotor de la formación de Juntas provinciales en Nueva España, con el que trabajaron muy unidos los miembros más jóvenes de la familia. Habia tratado de influir en Iturrigaray para que se desentendiera de los emisarios que llegaban de la península e instalara una Junta Provisional del Reino de Nueva España.

Francisco Fagoaga, hijo y hermano de los dos Marqueses del Apartado, al que Mier llamaba familiarmente «Frasquito", tenía casi la misma edad que Mina y desde muy joven había viajado por España y Europa. El año 1813 acompañó a su hermano José Francisco y a Vicente Rocafuerte en un largo viaje a través del continente. Llegaron hasta San Petersburgo y Alamán dice de ellos que sfueron siguiendo la retaguardia de los ejércitos rusos que empujaban a los franceses hacia el Elba, presenciando así el grande espectáculo que presentó el Norte, cayendo con todo su peso sobre el imperio francés".

\footnotetext{
38 Ver nota 28

39 Doris M. LADD, op. cit., pp. 180 y ss.

40 Charles HALE, Mexican liberalismo in the age of Mora. Yale, 1968. Hay edición española en Siglo xxI. David A. Brading. Mineros y comerciantes en el México borbónico. Fondo de Cultura Económica. México, 1985. John E. KizCA, "The great families of Mexico: Late colonial Mexico city», en Hispanic American Colonial Review. 62.3, 1982, y John Tutino, "Power, Class and family men and women in mexican elite". The Americas. 39.3, 1983.
} 
Siguiendo la pista de Vicente Rocafuerte ${ }^{41}$ sé que éste se encontraba en España a finales de 1813, porque tomó parte en algunas sesiones de las Cortes Generales, en las que era diputado por Guayaquil. Cuando Fernando disolvió las Cortes se negó a asistir a un besamanos al Monarca y, al parecer, escapó de España en compañía del conde de Toreno, cuya primera escala fue Londres. Permaneció en Europa hasta 1817, conoció a David Ricardo, al abate de Pradt y al barón de Humboldt y regresó a su país vía La Habana, donde frecuentó a sus amigos Fernández de Madrid y Miralla. Es probable que Francisco Fagoaga le acompañara en alguno de estos desplazamientos, aunque el año de 1815 lo pasó en Londres y tuvo un papel muy destacado en las conversaciones y arreglos previos, con la finalidad de organizar y preparar la Expedición de Mina a Nueva España.

José María Fagoaga se encontraba en la Península a finales de 1815, año de su llegada a España, después de su expulsión de Nueva España. La llegada a Londres debió ocurrir poco tiempo después. Noticias concretas de su estancia en Londres están datadas en torno al verano de 1816 , fecha de su encuentro con Bello en el Museo Británico, pero es seguro que entonces ya llevaba varios meses viviendo en la ciudad, que conocía de estancias anteriores.

Lucas Alamán ${ }^{42}$, amigo de los Fagoaga, debió llegar a Londres alrededor del mes de mayo de 1815 y permaneció en esta ciudad durante algún tiempo, hasta que decidió seguir viaje, junto con Francisco Fagoaga, para recorrer las ciudades más importantes del continente europeo. Aunque Alamán no se refiere en sus libros de historia a estos hechos, es obligado suponer que su contacto con los Fagoaga y sus propias inclinaciones juveniles le llevaran a conocer y participar en alguna de las conspiraciones que se estaban fraguando en Londres por aquellos meses. Lo confirma Palacio Fajardo, en carta de 29 de abril de 1815 a Aimé Bonpland escrita desde Londres, adonde acababa de llegar. Le dice: "El señor Alamán... ha prometido enviarme un cuaderno que usted le dio para mi (en Paris) y que es el proyecto de Constitución de nuestro pobre Dupont de Nemours, quien se dice ha dejado la Francia...". Era el momento en que Napoleón culminaba la aventura de los Cien Días, tras su regreso al continente. La carta nos muestra a un Alamán que participaba en el interés de sus compañeros por los temas políticos americanos.

4) A partir del excelente trabajo de Jaime E. Rodriguez, El nacimiento de Hispanoamérica. Fondo de Cultura Económica. México, 1980, la lectura de alguna de las obras de Rocafuerte y la amplia bibliografia dedicada a este tema.

42 Se pueden ver los escritos autobiográficos de Alamán, además de su Historia de Mégico. México, 1849-1852. 
Los datos biográficos que he podido recoger señalan que Lucas Alamán embarcó en Veracruz el 21 de enero de 1814 con destino a España, desde donde pasó enseguida a Francia para trasladarse poco después a Escocia y volver a París con la intención de presenciar la entrada de los ejércitos aliados. José $C$. Valadés ${ }^{43}$ dice que llegó a España en mayo de 1814 y permaneció un mes en Cádiz, visitando a continuación Sevilla. Se encontraba en Madrid a lo largo del mes de julio y en compañia de Miguel de Santa María y Pablo de la Llave fue un asiduo de las tertulias políticas de la capital. Esto me permite afirmar que tuvo que encontrarse y conocer a Xavier Mina y a su tío Espoz, que pasaron todo el mes de julio también en Madrid. Años más tarde, en su "Historia de Mejico...", se referirá por extenso y con cierta simpatía, a la Expedición de Mina.

Valadés cuenta con cierto detalle el periodo de estancia de Alamán en Madrid. Era amigo íntimo de Santa María, de quien Valadés dice que "hacía vida de hombre rico, siempre en contacto con los liberales". Alamán trató con los diputados mexicanos José Beye Cisneros y Ramos Arizpe, antes de su destierro. También contactó con Joaquín Lorenzo Villanueva, ex diputado por Valencia y perseguido por Fernando VII. Se entrevistó igualmente con el diputado Antonio Joaquín Pérez, representante de Puebla, que pertenecía al grupo de los "serviles" y fue premiado más tarde por el rey con el nombramiento de obispo de Puebla.

Frecuentó los salones del Marqués de Villafranca, donde se reunían españoles y americanos para hablar de letras, arte y política, buscando la amistad de algunos botánicos, dado su interés por esta ciencia. Valadés dice que salió de Madrid el 27 de septiembre y que el 1 de diciembre ya se encontraba en París, donde coincidió con Fray Servando Teresa de Mier, que le llevó a conocer a su amigo el abate Gregoire, jansenista y ex miembro de la Convención. Visitó al Barón de Humboldt y a Bonpland y conoció a Benjamín Constant y a Chateaubriand. Al parecer hizo algunos cursos de ciencias en el Colegio de Francia, pero el regreso de Napoleón le obligó a abandonar París el 13 de abril, en ruta hacia Londres, llevándose consigo al Padre Mier, que carecía de recursos propios para poder escapar. Hicieron el viaje vía Rouen y Dieppe, adonde llegaron el 25 de abril. En Londres, consiguió su permiso de residencia en el Alien Office el día 3 de julio.

En Londres coincidió con sus amigos Francisco y José Francisco Fagoaga, que llevaban algún tiempo viviendo en esta ciudad y se encontró también con José María Fagoaga, que llegó algo más tarde. Hizo amistad

13 José C. VALADÉS, Alamán, estadista e historiador. Robredo. México 1938. Reeditada por la UNAM en 1987 
con José María Blanco White y dijo de él que le enseñó todos los establecimientos científicos de Oxford. Alamán, en diciembre de 1815, regresó a Francia y allí esperó unos meses antes de iniciar un largo viaje por Europa, en el que le acompañó, durante algunos trayectos, Francisco Fagoaga.

En la investigación que me ha servido de base para redactar la tesis doctoral sobre Xavier Mina, se recogen las actuaciones posteriores de estos personajes y su implicación en mayor o menor medida en la Expedición del joven liberal español que en 1817 desembarcó en México, dispuesto a apoyar al general Morelos y al Congreso Mexicano. Desgraciadamente Mina llegó muy tarde a Nueva España, cuando Morelos había sido ya fusilado por los realistas y el Congreso se había disuelto. El propio Mina pereció fusilado el 11 de noviembre de 1817.

Los hispanoamericanos residentes en Londres, especialmente Palacio Fajardo, siguieron muy de cerca las vicisitudes de la expedición de Mina y lamentaron enseguida su desgraciado final. Todavia intentaron ayudarle armando una segunda expedición, que zarpó hacia Nueva York a finales de 1816, pero en cambio se vieron involucrados y fueron juguete de las circunstancias cuando el general y conspirador antifernandino Mariano Renovales decidió traicionar su confianza y se pasó, realmente "con armas y bagajes" al bando monárquico, en la fracasada expedición de 1817 a México.

Al iniciarse la tercera década del siglo, ocurrió una transformación inesperada: los liberales españoles regresaron a la península, buen número de patriotas hispanoamericanos se trasladaron a sus paises de origen y por otra parte, las oficinas de reclutamiento de oficiales y soldados, con perspectiva de hacer carrera en América, funcionaron a pleno rendimiento.

Fue un corto período de transición que se cerró muy pronto, cuando en 1823, tras el fracaso del Trienio liberal, volvieron o llegaron a Inglaterra miles de españoles que huian del terror fernandino. El final de las guerras de América, a partir de 1824, trajo también a varias decenas de enviados, embajadores o funcionarios de los nuevos gobiernos de las ex provincias españolas, en muchos casos las mismas personas que habian vivido años antes en Londres, con la finalidad de establecer relaciones diplomáticas, firmar acuerdos de cooperación o abrir nuevos horizontes a los intercambios comerciales y a la ayuda financiera.

Londres se convirtió en una potencia editorial en castellano, donde se publicaron libros y revistas, en un clima de libertad, muy favorable a la producción intelectual, tan magistralmente estudiada por Vicente Llorens ${ }^{44}$.

${ }^{44}$ Vicente LLORENS. Liberales y románticos. 1823-1834. Castalia. Madrid, 1979. 